\title{
Compaction and Strength Properties of Road Subbase Infused with a Latex Copolymer
}

\author{
Noor Hadijah Abdul Hadi', Soon Jiann Tan', El-Said Mamdouh Mahmoud Zahran, Muneerah Jeludin², \\ Tan Eng Hie ${ }^{2}$ \\ ${ }^{1}$ Centre for Transport Research, \\ Universiti Teknologi Brunei, Brunei Darussalam \\ hadijah.hadi@utb.edu.bn, soonjiann.tan@utb.edu.bn, elsaid.zahran@utb.edu.bn, \\ ${ }^{2}$ Civil Engineering Programme Area, \\ Universiti Teknologi Brunei, Brunei Darussalam \\ muneerah.jeludin@utb.edu.bn, angelteh86@gmail.com
}

\begin{abstract}
There are significant challenges to the design and construction of roads and highways worldwide. There are many contributors to these challenges, including weak subgrade soil. This paper investigates the potential to stabilise and improve the compaction and strength characteristics of a road base through infusion with a non-hazardous latex copolymer dispersion. Brunei Darussalam was selected as a case study for this research due to the abundance of soft clay and peat in a large part of the country. In recent years, major serviceability issues, including undulating pavement surfaces due to differential settlement, have emerged on several local roads and highways built on these weak grounds. Standard laboratory tests were conducted to evaluate the short-term improvement in engineering properties of the stabilised soil-aggregate mixture. Five cylindrical specimens were prepared in standard compaction molds with polymer contents of $0 \%$ (control), $0.5 \%, 0.75 \%, 1 \%$, and $2 \%$ concentrations by mass. The particle size distribution of the soil-aggregate mixture was first determined using standard laboratory sieve analysis, before the compaction characteristics (i.e. optimum moisture content and maximum dry density) of each specimen was determined using Proctor compaction tests. Further specimens were prepared under their respective optimum moisture content to be tested using unconfined compression test. Results indicated that the maximum dry density of the subbase-polymer mixture decreases with increasing polymer content. Adding $0.5 \%$ polymer doubled the strength of control mixture in terms of unconfined compressive test results. However, increasing the polymer content beyond $0.5 \%$ did not significantly increase the compressive strength any further. This can help to produce guidelines for application of the polymer to achieve a cost effective design alternative that may improve surface conditions and ride quality of roads on weak subgrade soil.
\end{abstract}

Keywords: Polymer, Pavement, Stabilization, Lab testing.

\section{Introduction}

Most parts of Brunei Darussalam consisted of large deposits of soft clay and peat, resulting in soft and weak grounds. Flow of goods via heavy good vehicles usually involves the application of heavy traffic loads to pavement layers [1]. In recent years, major serviceability issues, including undulating pavement surfaces due to differential settlement, have emerged on several local roads and highways built on these weak grounds. Hence, road construction over these soils typically required costly foundations or soil replacements. Other economical solution to the problem is by stabilising the subgrade using inclusions such as lime, Portland cement or fly ash, to improve the stiffness and strength of weak subgrade. Studies show that stabilisation of weak or soft subgrade improves the strength properties and load carrying capacity. Consequently, it reduces excessive deformation and settlement of the layers above the stabilised or treated subgrade. These soil stabilisation methods typically involve changes in the soil properties, such as increasing unit weight, reducing permeability, and limiting volume changes. In recent years, there is a growing trend to replace the application of cement or other cementitious additives as soil stabilizers to a more eco-friendly material which is liquid polymer-based stabilizers [2][3]. Polymer are especially suited for treating poorer quality soils particularly in areas where periodic flooding occurs. Several concerns were identified with the use of lime as soil stabilisers, i.e. lime carbonation, sulphate attack and carbon dioxide emission. Moreover, it was found that, soil treated with lime or calcium-base additives consisting soluble sulphate salt will cause the soils to experience distress, heaving and disintegration [4]. The use of "Class F" fly ash, on the other hand, requires as activator in the form of 
either lime or cement to form pozzolanic stabilised mixtures, as fly ash inherently is not a self-cementing material [5][6]. One notable advantage of using liquid soil stabilizer is that it reduces the hazards associated with dust dispersion by powder form of soil stabilisers. One of the earliest reported applications of acrylic polymers as a soil stabilisers [7] concluded that the polymers have the potential to improve and stabilise soils economically. However, the pioneering research and experimental programme was not able to provide specific recommendations for general applications to soil stabilisations [7]. Several researchers have reported advances specific to the applications of polymer stabilisers to improve the performance of soils. An investigation into the use of polymer in silty-sand soils resulted in increased strength under both wet and dry conditions [8]. [9]stabilised the subbase and base layer of Jalan Tutong and Junjungan Road in Brunei Darussalam using polymer modified cementitious chemical binder. The rise in unconfined compressive strength of the stabilised layers ranged from 0.75 to $6.00 \mathrm{MPa}$.

T-PRO ${ }^{\circledR} 500$ is a commercially available non-hazardous latex copolymer dispersion designed for soil stabilisation and dust suppression for a verity of soil types [10]. It has previously been found that the addition of T-PROß 500 has significantly increased the strength and durability of polymer-modified mortars (PMMs) when compared with untreated PMMs [11]. Nevertheless, as polymer-based soil stabiliser has not been widely adopted in Brunei Darussalam, there is a need to demonstrate the benefits of replacing traditional soil. Stabilisation methods with polymeric materials, including their application to improve pavement performance, in road construction project. This paper investigates the potential to stabilise and improve the compaction and strength characteristics of a road subbase through infusion with a commercially available polymer, T-PROß 500 . In particular, the influence of varying the proportion of polymer in samples of laboratory-prepared clay-aggregates mixture is presented. The compaction properties are characterised by the optimum water content and maximum dry density, while the strength is characterised by the unconfined compression strength.

\section{Material Properties}

\subsection{Clay}

In this study, Kaolin grade KM40 was used and the properties are presented in Table 1.

Table 1: Properties of Kaolin.

\begin{tabular}{|l|l|}
\hline \multicolumn{2}{|c|}{ Kaolin (KM40) } \\
\hline Physical Properties & $<2 \%$ \\
\hline Moisture content & $4-5.5$ \\
\hline $\mathrm{pH}$ (30\% solid) & $76-80 \%$ \\
\hline Brightness & $2.5-3.5$ micro \\
\hline 325 Mesh Residue \\
\hline Chemical composition & $32-38 \%$ \\
\hline Aluminium & $47-57 \%$ \\
\hline Silica & $11-14 \%$ \\
\hline Loss on ignition @ $1025^{\circ} \mathrm{C}$ & \\
\hline
\end{tabular}

\subsection{Aggregate}

Coarse and fine aggregates used in this study were obtained from various local sites and prepared in accordance with BS1377-2:1990:9.3. The coarse and fine aggregates were initially separated by sieving into the sizes of $20 \mathrm{~mm}, 14$ $\mathrm{mm}, 10 \mathrm{~mm}, 5 \mathrm{~mm}, 3.35 \mathrm{~mm}$, and $2.0 \mathrm{~mm}, 600 \mu \mathrm{m}, 300 \mu \mathrm{m}, 150 \mu \mathrm{m}, 63 \mu \mathrm{m}$ respectively. The aggregates size distribution is shown in Fig. 1. In this study, the specifications for aggregate gradation were taken from [16]. 


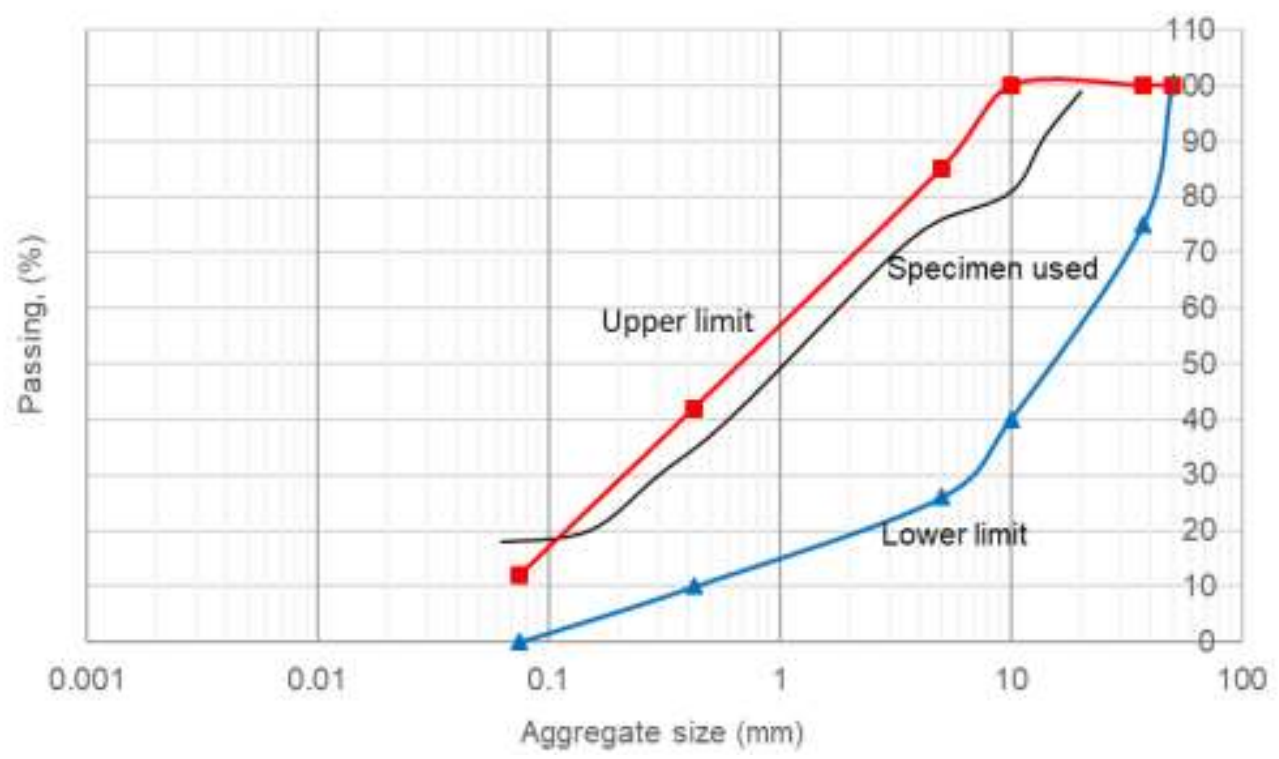

Fig. 1: Aggregate size distribution.

\subsection{Polymer}

T-PRO ${ }^{\circledR}$ 500, explained in Section 1, was used as a binder polymer for subbase layer material in this study. Table 2 shows the chemical properties of the binder.

Table 2: Chemical properties of T-PRO® 500.

\begin{tabular}{|l|l|}
\hline \multicolumn{2}{|c|}{ CHEMICAL PROPERTIES } \\
\hline Physical Form & Liquid \\
\hline Color & White \\
\hline Odor & Characteristic \\
\hline Flash Point & Not applicable \\
\hline Vapor Pressure & $17 \mathrm{mmHg} @ 20^{\circ} \mathrm{C}$ \\
\hline Solubility in Water & Miscible in all proportions \\
\hline pH & $6.0-9.0$ \\
\hline Viscosity & $<500 \mathrm{cSt}$ (estimated) \\
\hline Total Solids & $>50 \%$ \\
\hline Minimum Film From Temperature & $7^{\circ} \mathrm{C}\left(45^{\circ} \mathrm{F}\right)$ \\
\hline Specific Gravity & $0.95-1.10$ \\
\hline Particle Size & $125 \mathrm{~nm}$ \\
\hline
\end{tabular}

\section{Experimental procedure}

\subsection{Sample preparation}

In the present study, the sample preparations and subsequent investigations followed the procedures of BS 1377-1: 2016. Coarse and fine aggregates, together with the clay powder, were prepared and proportioned according to the grading requirement, and thoroughly mixed before the required amount water was added to achieve a particular target water content. For samples treated with polymer, the dispersion was added to the aggregate and clay mixture together with water of the correct proportion to reach the target water content. Polymer of different contents; $0.5 \%, 0.75 \%, 1 \%$ and $2 \%$ were mixed with aggregate to evaluate the effect of polymer addition on the strength characteristics of the mixture. 


\subsection{Moisture content-dry density relationship of the mixture}

The relationship between the water content and the dry density of specimen was determined in accordance with BS 1377-4: 1990: 3.3 using a standard proctor compaction test. Each mixture was compacted according to the section 3.3.4.1. Two small samples were extracted from each sample group, placed in a separate container and immediately transferred to an oven for the determination of its moisture content. Thus, optimum moisture content (OMC) and maximum dry density (MDD) were obtained from Figure 2.

\subsection{Unconfined compressive strength}

The primary purpose of the UCS test is to determine the approximate compressive strength of mixtures in unconfined state. The tests were conducted on specimens compacted to MDD and OMC obtained from the Standard Proctor test. All the specimens for the UCS test were prepared according to BS 1377-1: 2016. The specimens were removed from the mould using a sample extruder and subsequently cured for 3 and 7 days in the moist room at $25^{\circ} \mathrm{C}$. Two specimens of each group mixture were prepared in the manner described in BS 1377-1. Each specimen was subjected to UCS test once the designated curing period was complete.

The UCS of each specimen was determined using a compressive strength testing machine according to BS 1377-7: 1990: 7.2. The load was applied to each specimen at a constant rate of $0.01 \mathrm{MPa} / \mathrm{s}$. Each specimen was compressed until it collapsed.

\section{Results and discussion}

\subsection{Effect on the compatibility}

The test results of standard proctor tests are presented in Table 3, and the compaction curves are shown in Fig. 2.

Table 3: Compaction property.

\begin{tabular}{|l|c|c|c|c|c|}
\hline Polymer concentration & $\mathbf{0 \%}$ & $\mathbf{0 . 5 \%}$ & $\mathbf{0 . 7 5 \%}$ & $\mathbf{1 \%}$ & $\mathbf{2 \%}$ \\
\hline Optimum moisture content $(\%)$ & 7.2 & 8 & 9 & 9 & 10 \\
\hline Max. dry density $\left(\mathrm{Mg} / \mathrm{m}^{3}\right)$ & 2.17 & 2.05 & 2.03 & 2.03 & 2.01 \\
\hline
\end{tabular}

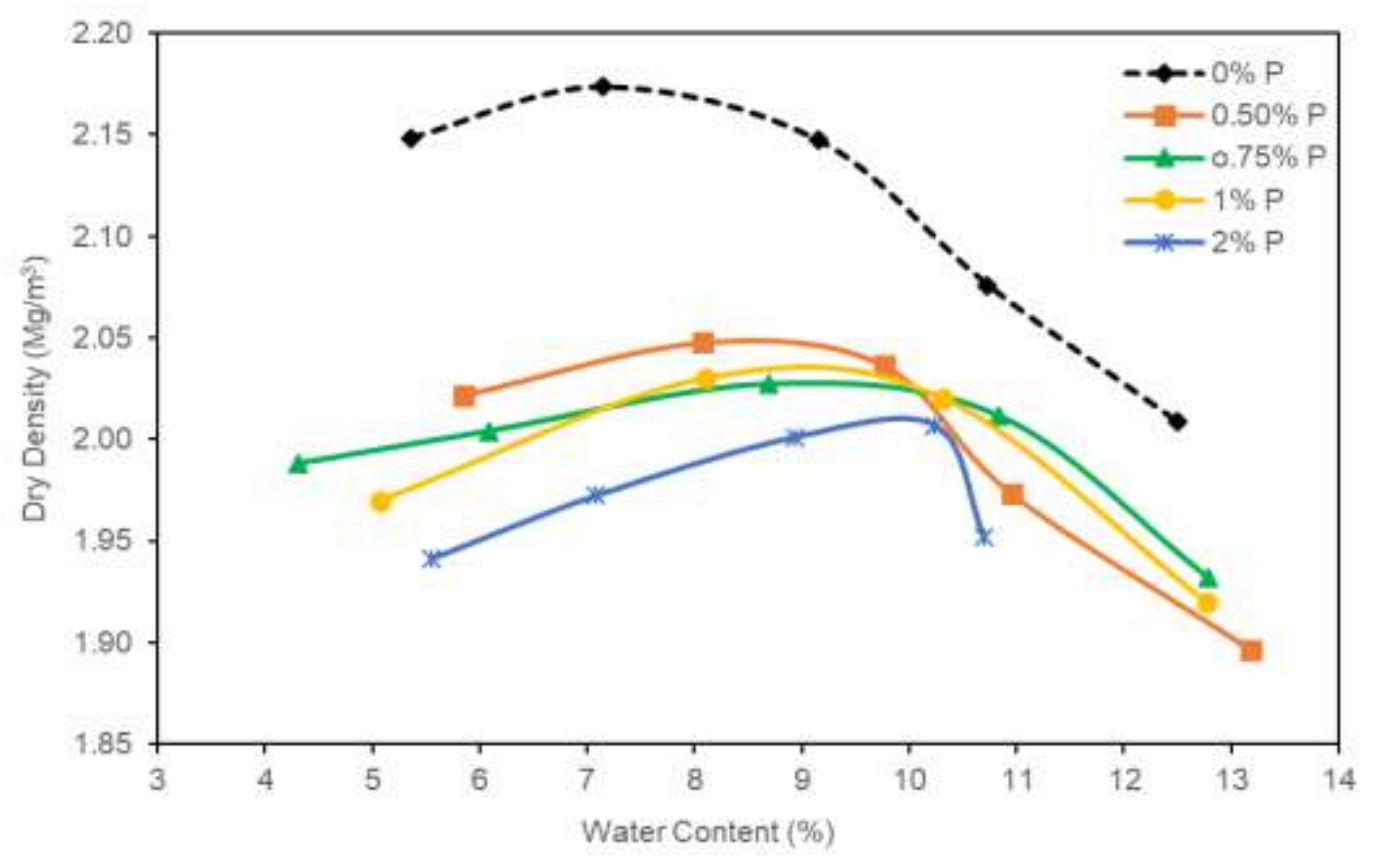

Fig. 2: Relation between dry density and water content for various polymer contents ("P" denotes polymer). 
It is found that the MDDs were decreased and OMCs were increased with the addition of polymer. The dry density value decreased from $2.17 \mathrm{Mg} / \mathrm{m}^{3}$ to $2.01 \mathrm{Mg} / \mathrm{m}^{3}$ and the $\mathrm{OMC}$ was increased from $7.2 \%$ to $10 \%$ with the addition of $2 \%$ polymer by dry weight of soil mixture. Fig. 3 shows the influence of polymer content on MDD. The reduction in MDDs with the addition of polymer can be attributed to the reduction of average unit weights of solids in the soil mixture.

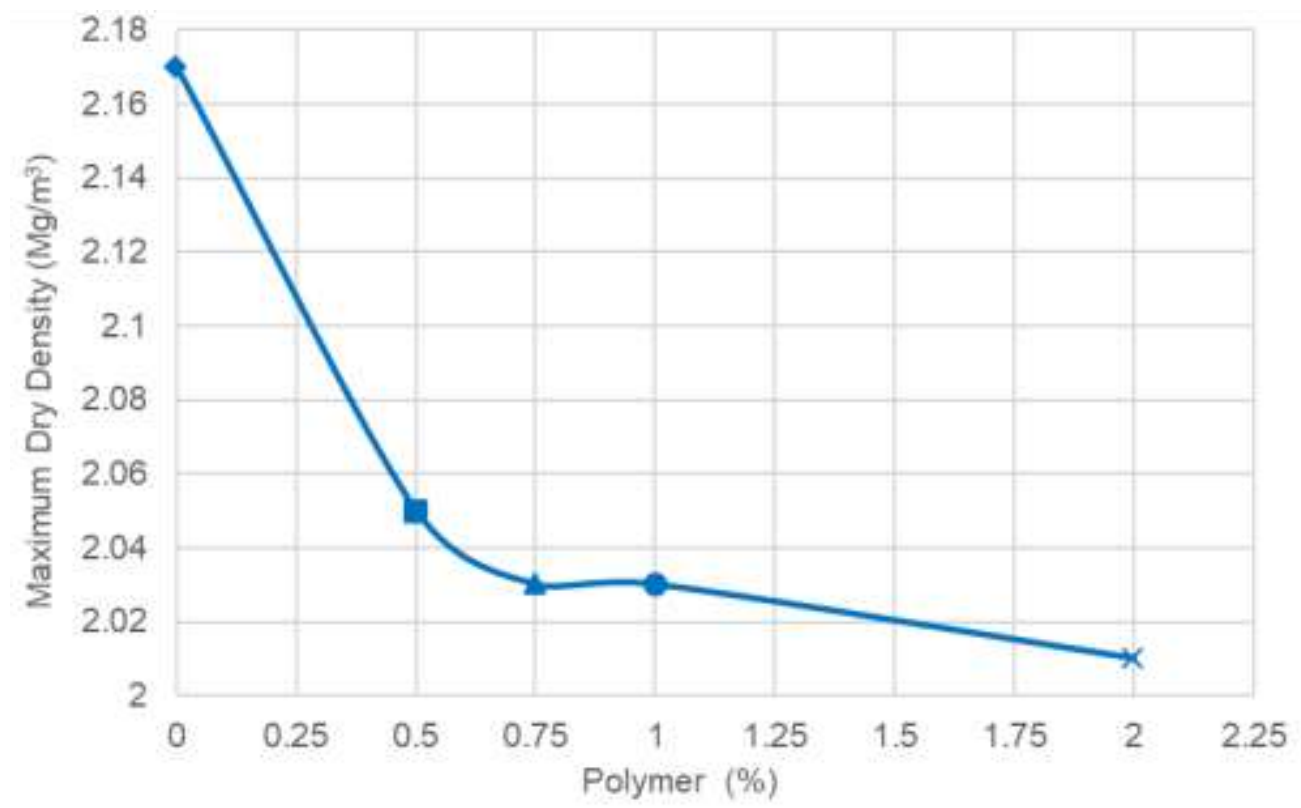

Fig. 3: MDD vs Polymer content.

\subsection{Effect on the compressive strength}

The UCS results for samples at various polymer contents cured for 3 and 7 days is presented on Table 4. It was observed that there is no significant gain in strength between the unstabilised control specimen and the $0.5 \%$ stabilized specimen for $0 \mathrm{hr}$ curing time as polymerisation has not yet occurred and moisture has not yet evaporated. In addition, as shown in Figure 4, curing time affect the UCS of the stabilised specimens. The UCS for specimens cured for 7 days shows increased in strength when compared to specimens cured for 3 days. For $0.5 \%, 0.75 \%, 1 \%$ and $2 \%$ polymer contents, the results in Table 4 indicated that the compressive strength obtained after curing for 3 days increased by approximately $89 \%, 109 \%, 83 \%$, and $54 \%$, respectively. Whereas for $0.5 \%, 0.75 \%, 1 \%$ and $2 \%$ polymer contents, the results in Table 4 indicated that the compressive strength obtained after curing for 7 days increased respectively by $94 \%, 123 \%, 120 \%$, and $100 \%$. Polymer infusion improved the polymer-stabilized specimen properties due to the vaporization process of water as a result of chemical interaction that took place between the polymer and other aggregate particles in the mixture [12], [13], [14] and [15]. From the curves shown in Figure 5, it shows that the $0.75 \%$ stabilized specimen reaches the highest compressive strength value for 3 days and 7 days curing time than the other stabilized specimens in this study $(0.5 \%, 1 \%$ and $2 \%)$. The $0.75 \%$ stabilized specimen showing a two-fold increase in strength after 3 days curing compared to the strength for 0 day of curing. However, at concentrations higher than $0.75 \%$, the UCS decreased with increasing polymer content, due to the higher water content of polymer which might have led to a decrease in the MDD and strength of the mixture. This agrees with the rise range in UCS of stabilised road layers by [9], as shown earlier in Section 1.

Table 4: UCS values.

\begin{tabular}{|lc|c|c|c|c|c|}
\hline \multicolumn{2}{|l|}{ Polymer concentration } & $\mathbf{0 \%}$ & $\mathbf{0 . 5 \%}$ & $\mathbf{0 . 7 5 \%}$ & $\mathbf{1 \%}$ & $\mathbf{2 \%}$ \\
\hline UCS $(0$ day $)$ & $(\mathrm{Mpa})$ & 0.35 & 0.35 & - & - & - \\
\hline UCS $(3$ day $)$ & $(\mathrm{Mpa})$ & - & 0.66 & 0.73 & 0.64 & 0.54 \\
\hline UCS $(7$ day) & $(\mathrm{Mpa})$ & - & 0.68 & 0.78 & 0.77 & 0.70 \\
\hline
\end{tabular}




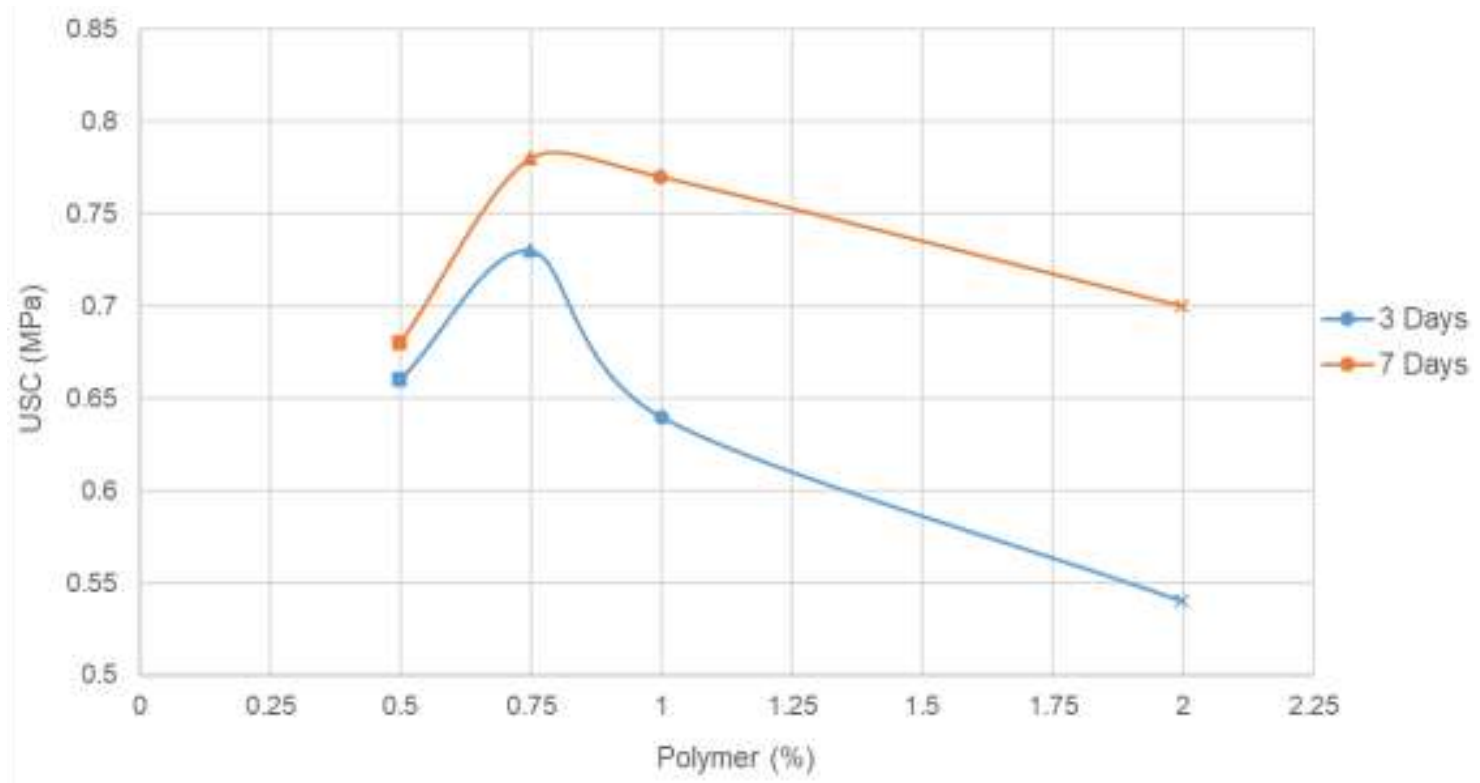

Fig. 4: UCS vs Polymer content for 3 and 7 days.

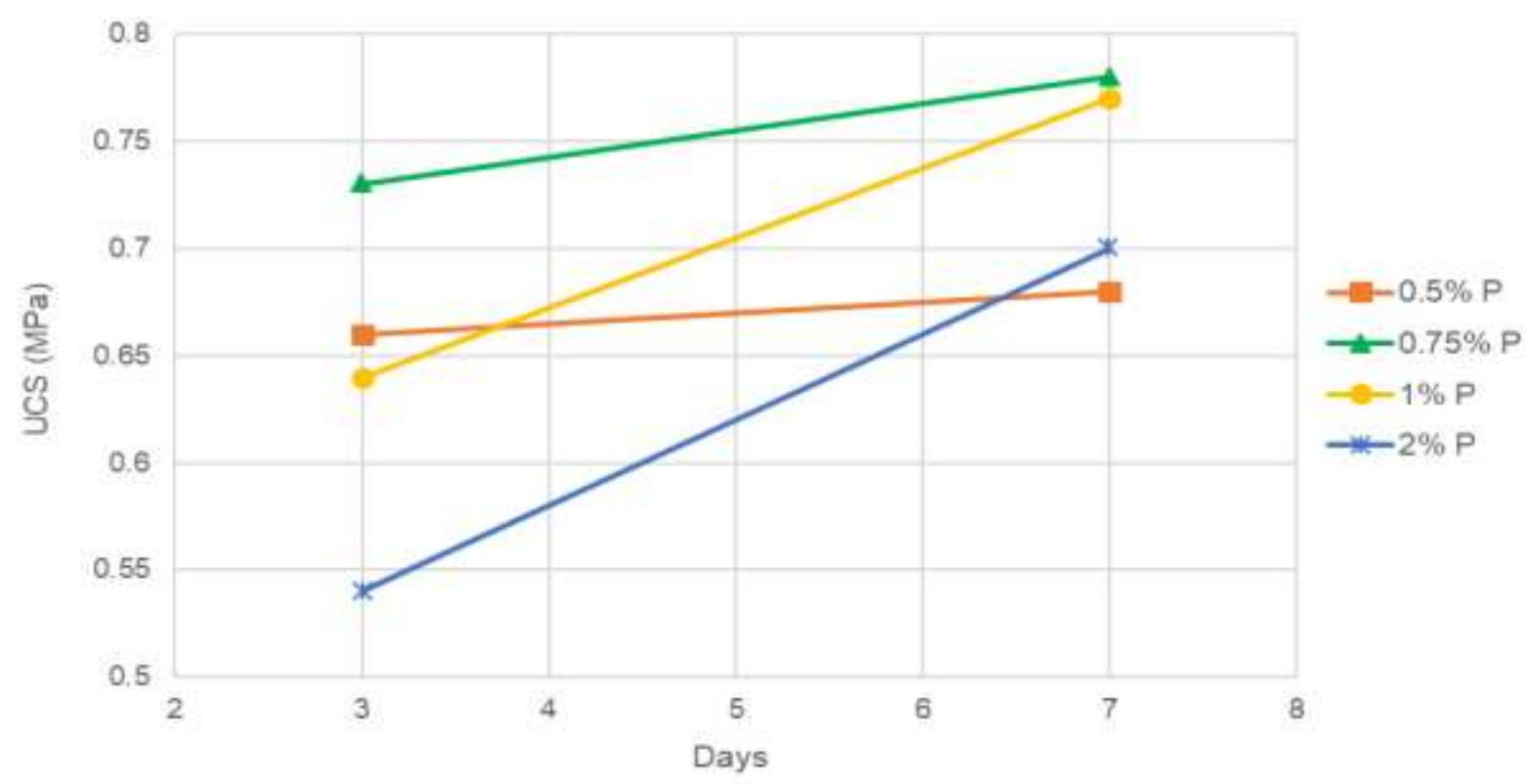

Fig. 5: UCS vs Curing time.

\section{Conclusion}

The short-term improvement in engineering properties of the stabilised subbase road layer in this study was evaluated via standard proctor compaction and UCS tests. With respect to compaction, adding polymer to the mixtures increased MC however decreased MDD. The UCS of specimen was improved significantly with the addition of the $0.5 \%$ polymer content compared to the control specimen ( $0 \%$ polymer content). However, the UCS decreased when polymer content exceeded $0.75 \%$. Specimen prepared with $0.75 \%$ polymer content exhibited the highest strength obtained in this study, thus recommended as the optimum content of polymer in the pavement subbase layer. The results of this study also indicated that the UCS was improved by increasing the curing time to 7 days. Hence, the preliminary findings of this paper indicate that the polymer employed in this study can stabilise subbase layers of similar properties to those of this paper's subbase layer. 


\section{Acknowledgements}

The authors are grateful to Terratech Earth Solutions Limited for providing the polymer used in the laboratory experiments and its technical specification.

\section{References}

[1] S. A. Sholihah, T. M. A. Ari Samadhi, A. Cakravastia, and S. N. Bahagia, "Coordination model in hinterland chain of hub-and-spoke export trade logistics," Journal of Industrial Engineering and Management, vol. 11, no. 4, pp. 776793, 2018.

[2] I. Chang, J. Im, and G. C. Cho, "Introduction of microbial biopolymers in soil treatment for future environmentallyfriendly and sustainable geotechnical engineering," Sustainability (Switzerland), vol. 8, no. 3. 2016.

[3] N. Latifi, S. Horpibulsuk, C. L. Meehan, M. Z. Abd Majid, M. M. Tahir, and E. T. Mohamad, "Improvement of Problematic Soils with Biopolymer-An Environmentally Friendly Soil Stabilizer," J. Mater. Civ. Eng., vol. 29, no. 2, pp. 04016204, 2017.

[4] I. T. Jawad, M. R. Taha, Z. H. Majeed, and T. A. Khan, "Soil stabilization using lime: Advantages, disadvantages and proposing a potential alternative," Res. J. Appl. Sci. Eng. Technol., vol. 8, no. 4, pp. 510-520, 2014.

[5] A. A. Firoozi, C. Guney Olgun, A. A. Firoozi, and M. S. Baghini, "Fundamentals of soil stabilization," Int. J. GeoEngineering, vol. 8, no. 1, pp. 26, 2017.

[6] S. Mahvash, S. López-Querol, and A. Bahadori-Jahromi, "Effect of class F fly ash on fine sand compaction through soil stabilization," Heliyon, vol. 3, no. 3, pp. e00274, 2017.

[7] A. A. Fungaroli and S. R. Prager, "Evaluation of some acrylic polymers as soil stabilizers," Ind. Eng. Chem. Prod. Res. Dev., vol. 8, no. 4, pp. 450-453, 1969.

[8] R. L. Santoni, J. S. Tingle, and S. L. Webster, "Stabilization of silty sand with nontraditional additives," Transp. Res. Rec., no. 02, pp. 61-70, 2002.

[9] C. T. Group, “A Green and Effective Approach for Pavements in Tropical Region,” pp. 1-12, 2011.

[10] I. T-pro, "www.terratechinfo.com."

[11] A. Parghi and M. Shahria Alam, "Effects of curing regimes on the mechanical properties and durability of polymermodified mortars - an experimental investigation," J. Sustain. Cem. Mater., vol. 5, no. 5, pp. 324-347, 2016.

[12] A. B. Moustafa, A. R. Bazaraa, and A. R. N. El Din, "Soil stabilization by polymeric materials," vol. 91, no. 1390, 1981.

[13] K. Newman and J. S. Tingle, "Emulsion polymers for soil stabilization,” no. April, pp. 18, 2004.

[14] M. Shojaei Baghini, A. Ismail, M. R. Karim, F. Shokri, and A. A. Firoozi, "Effect of styrene-butadiene copolymer latex on properties and durability of road base stabilized with Portland cement additive," Constr. Build. Mater., vol. 68, pp. 740-749, 2014.

[15] M. S. Baghini, A. Ismail, S. S. Naseralavi, and A. A. Firoozi, "Performance evaluation of road base stabilized with styrene-butadiene copolymer latex and Portland cement," Int. J. Pavement Res. Technol., vol. 9, no. 4, pp. 321-336, 2016.

[16] MOD, 1998: General Specification for Flexible Pavement, Ministry of Development, Brunei Darussalam. 